\title{
An ethical examination of the challenges of in-vitro fertilisation in Nigeria
}

\author{
Daniel D. Bingel \\ Federal College of Education, Private Mail Bag 27, Pankshin, Nigeria
}

\begin{abstract}
It is the position of this paper that the availability of In-Vitro Fertilisation (IVF) treatment clinics in Nigeria's healthcare system has moral implications which are as yet not fully considered nor critically understudied. The paper argues that the availability of such procedures ought to be properly considered and the many ramifications it may have to individuals as well as to national values be comprehensively examined at this early stage before it becomes widespread so as to preserve both our national values and the good of the individual citizen. It proceeds by identifying the need for Nigeria as a country to dedicate resources for research based innovations; it also examines the practice of IVF in Nigeria highlighting history, procedure and accessibility. The paper then proceeds to discuss some challenges of IVF in Nigeria before arguing that there are moral objections to IVF that call for national discussion at an early stage. It concludes that IVF has the potential to change the values of Nigerians and it would be wise if these values change consciously rather than unconsciously.
\end{abstract}

Keywords: Infertility; In-Vitro Fertilisation; Values; fertility treatment

\section{INTRODUCTION}

Worldwide, new innovations in healthcare delivery have advanced based on various researches that have contributed in no small measure to better understanding of the human body and how it functions. These advances have been recorded largely because dedicated researchers have undertaken bold experimentations on the human body that are both time-taking and expensive. Most of these experiments have come at high cost to the human person; these costs can be identified both in terms of the personal sacrifice of willing individuals involved in these studies, especially the test subjects, and on the moral level by the unsolicited subjects of experimentation and the society that has permitted it.

Nigeria is still yet to record its name among the nations known for research-based innovation even though there are many breakthroughs that have been credited to Nigerians working in other countries that have large budgets dedicated to research. Sanusi (2013) ranked the country low in research capacity and called for the building of research communities and the re-enforcement of their capacities to be made a national priority. For the larger part, Nigeria remains a consumer society, consuming mostly in whole the innovative products of other nations whose research base is stronger. The immediate implication of this is that sometimes, Nigeria accepts the goods from these nations along with the bad and the ugly.

This paper argues that the emergence of infertility clinics, specifically In-Vitro Fertilisation (IVF) clinics and treatment centres is a case at point. It proceeds by tracing the experimental process involved in developing IVF, highlighting the benefits of IVF and $\mathrm{x}$-raying 
the moral objections that are attendant to IVF in order to propose a course of decision making for Nigeria as a nation with unique values to protect.

\section{IVF PRACTICE IN NIGERIA}

Infertility constitutes one of the most trying challenges of the married state. In Africa it is a national health problem in many countries affecting $10-32 \%$ of couples on the average (Shahin, 2007, p. 51). In Nigeria, studies have shown that the prevalence rate of infertility is about $25 \%$, with 1 in 4 women of child-bearing age experiencing delay in conception (Ajayi and Osadolor, 2011, p. 80). A variety of factors contribute towards making the plight of infertile women worse like cultural beliefs, social stigmatisation and a common association of infertility with nemesis (Ukpong and Orji, 2006). Due to these social and cultural factors associated with motherhood, many Nigerian women go the extra mile, both spiritually and temporally, seeking the blessings of 'the fruit of the womb'. In-Vitro Fertilisation (IVF) has recently become very attractive in Nigeria, representing the definite solution to barrenness and stigmatisation, because unlike many of the more traditional ways of seeking fertility, it is both medically accepted and socially tolerated (Shahin, 2007).

Since the first 'test-tube baby', Louise Brown, was born in 1978 to British parents, many children have been born through Assisted Reproductive Technologies. According to Ola (2012), virtually all forms of Assisted Reproductive Technologies (ARTs) are available in Nigeria. She opined, "The Lagos University Teaching Hospital team of Giwa- Osagie, Ashiru and Abisogun produced documented pregnancies through IVF in 1984, 1986, and a live birth in 1989. The first baby born in West Africa as a result of IVF was delivered at the Lagos University Teaching Hospital in 1989" (p. 332). Over the past two decades, the number of fertility centres and their sophistication has increased in Nigeria.

The procedure of IVF involves first 'switching off' a woman's natural cycle of egg production in the ovaries (down-regulation) (NICE, 2004, p. 41), the ovaries are then stimulated to produce multiple eggs (super-ovulation), these eggs are then surgically removed, and fertilised in a laboratory dish with the treated sperm of the father (or donor) outside the body (in vitro). Once the eggs have been fertilised, they are left to grow (for up to $48 \mathrm{hrs}$ ) till they reach the eight-cell stage of development. The healthiest and promising few may then be transferred into the uterus of the same woman or a surrogate so that pregnancy results (Elder and Dale, 2000). Usually, two or three of the more promising ones are transferred to increase the chances of implantation and of pregnancy resulting.

The provision of IVF services in Nigeria is at present largely a private sector endeavour, with only a few IVF centres within the public sector. However, the proliferation of these centres across the country makes it imperative that specific concern should be noted about them by the government and regulatory bodies concerned. According to Ajayi and Osadolor (2011), "This private sector dominance of the IVF field is informed by a population whose healthcare needs far outweigh its capacity to meet them" (p. 80). With Nigeria still grappling with poor healthcare statistics, advanced medical care such as available through IVF does not seem to constitute a pressing issue. 


\section{CHALLENGES OF IVF IN NIGERIA}

Since the introduction of IVF to the Nigerian medical field, there has been a noticeable lack of public discussion on the many issues that usually surround such extra-natural treatment of the human person. This lack of discussion has left IVF to develop in Nigeria without much hindrance and with virtually no regulation. Ajayi and Osadolor (2011), Ola (2012) and Osazuwa (2013) agreed that there is a despicable lack of regulation for IVF in the country which makes couples seeking the treatment defenceless in the face of all sorts of exploitative practices. Citing Giwa-Osagie, Osazuwa (2013) held that, "Regulatory framework for fertility treatment in the country had continually put couples in need of IVF on the vulnerable edge" (p. 7). The need for regulation cannot be overemphasised as most countries who have accepted Assisted Reproduction Technologies (ARTs) have also set up bodies to regulate the practices. It is unclear whether or not Nigeria has accepted the practices since though the reality of fertility treatment is evident in the society, national dialogue on the issue has not commenced so as to set a framework within which these services can be made available in the country. There presently exist no laws to moderate the practice and guide practitioners despite the fact that IVF is subject to many contentious issues. For now, most guidelines are based on regulatory bodies based in Europe and America (Osazuwa, 2013).

Another important and pressing challenge of IVF in Nigeria is access to care. While virtually all the existing clinics where IVF treatment can be accessed in Nigeria are in highly urban cities and within the private sector, thereby making it difficult for remotely located couples to conveniently attend the elaborate examinations required for IVF and to access treatment, the cost of a single cycle of IVF treatment makes it a preserve of only a limited group of Nigerians. Ola (2012) observed that, "Access to ART is limited by cost. It is not easily affordable because it is an expensive procedure. In Nigeria, a cycle of IVF cost about US\$2000 - US\$ 2700 (250,000 to 350,000 Naira). Therefore, for an average Nigerian, ART is not currently affordable and easily accessible since it is not done in the public sector because of lack of funds except in the private sector" (pp. 332-333). With a success rate averaging $25 \%$ some couples may need up to two or three cycles of treatment before pregnancy results.

Furthermore, in the absence of proper regulation, it is hard to determine whether all those who claim to give the specialised treatment IVF requires are actually qualified to give it. Though there are recognised researchers in the line of medical care who have dedicated time and resources towards IVF specialisation, the possibility of persons without proper specialisation in IVF exploiting unsuspecting couples exists (Shahin, 2007). With continuing research in the procedure of IVF, there is need to ensure that IVF centres are up to date regarding procedures and equipment.

\section{MORAL OBJECTIONS TO IVF: THE NEED FOR NATIONAL DIALOGUE}

A template for addressing controversies in IVF as spelt out by Osazuwa (2013) includes: medical as well as ethical, socio-economic, legal and religious issues. Medical issues include the low success rate of IVF treatment (only about $25 \%$ per cycle i.e. $1 / 4$ ) compared to the high cost of one cycle of treatment, medical risks involved-including the risk of ovarian cancer and the intense emotional and physical pain experienced by patients (Fisk, 2004). There is need for careful regulation of the medical practice to minimise risk to patients and to protect them from further complications that are unnecessary. 
However, some moral objections need to be carefully spelt out so as to set a path to national dialogue. For ease of discussion it suffices to examine the controversial issues under the following broad headings: Issues regarding IVF procedure, issues regarding non-coital parenthood, issues regarding the treatment of the embryo.

\section{a. Objections to IVF procedure}

The procedure for IVF implies harvesting male and female sex gametes i.e. the sperm and the ova. Some objections have been raised regarding the process of harvesting these. On the one hand, the method of getting the sperm usually involves masturbation, which is a moral problem for some since masturbation is considered by them to be an immoral and inexcusable act; on the other hand the procedure for retrieving the oocytes involves super-ovulation and laparoscopy, which research says is psychologically traumatising especially in cases where there is no success in implantation.

Dominguez-Urban (2005) explained that, "Because 'harvesting' ova is expensive and invasive, women are often hormonally induced to produce several ova. Often, physicians implant multiple embryos to increase the chances of live births; this procedure increases the possibility of multiple births or selective abortion if too many embryos are implanted" (p. 721). The hormonal distortion necessary for IVF treatment is considered as an unnatural tempering with the human person.

Some have even argued that the very possibility of fertilisation taking place outside the human body is an extraordinary and unnatural development that amounts to humans claiming the power to procreate; a capacity which is the preserve of the Author of Life. Carnley (2002) argued that in assisting the sperm to overcome a natural barrier, we in effect 'play God'. He said,

Perhaps the sperm is not making it, as it were, because it carries some genetic defect that would issue in some kind of inherited disease in the resulting child. In other words, perhaps there is a natural or God-given reason for screening out or not letting in some sperm. Are we running the risk of engineering deformities and inherited diseases by helping overcome a naturally erected barrier? In theological terms are we unwittingly thwarting the good purpose of God? I note that some resent (sic) research indicates that deformities are twice as likely in IVF children as in children naturally conceived, though $90 \%$ if IVF children are nevertheless born without defects (p. 1).

Hence, on the basis of the moral objection to masturbation and the deliberate tampering of the human person, many religious groups have traditionally been opposed to IVF and other ARTs.

\section{b. Non-coital parenthood}

The Roman Catholic Church and some non-catholic theologians have opposed all techniques that do not involve direct sexual intercourse between a man and his wife as means for reproduction including AI (Artificial Insemination), IVF, Surrogate motherhood, AID etc. because they separate the marital and reproductive functions of love (Dominguez-Urban, 2005).

The fact of reproduction without coitus has opened the sexual act to a lot of problems. Because many instances of infertility have known causes, there are instances of people demanding careful selection of their offspring resulting from IVF so as to avoid genetically inherited diseases or even to select the sex of their offspring. "Those against it have argued that sex selection is playing God-by interfering with the natural process of reproduction; that it harms children-by treating them as means to one's whims rather than treating them as ends; and 
that it harms women because in many countries, there is a bias in favour of having male offspring and sex selection can contribute to this bias" (Liao, 2004, 1).

Sunni Islam, comprising of about $90 \%$ of the world's Muslims, is also opposed to any form of reproduction that involves a third party. Hence, the common practice in IVF of getting one or both the sex gametes from donors in cases of defective genes present in the gametes of the parents, or even of using surrogates is prohibited. The leading authority in this matter remains the guiding fatwa issued in 1980 by the Grand Sheikh of Egypt's famed Al Azhar University, which effectively allows IVF with restriction on all third-party involvement, i.e. donors and surrogates (Inhorn, 2006, p. 44).

As has been documented in some cases, non-coital parenthood presents some legal difficulties also. Because of the involvement of so many hands in the conception and success of childbirth, it is hard to conclude how the offspring stands in relation to each individual involved. A feminist writer, Greer (1999), commented, "The relentless advance of reproductive technology has now split mother hood into three compartments, genetic motherhood, gestational motherhood and parental motherhood... Nobody really knows whether a genetic mother has more entitlements to claim a child than the woman who grew and nourished it in her womb or the woman who rears and nourishes it outside the womb" (p. 70).

\section{c. Status and treatment of embryos}

When a single embryo is implanted through IVF such that pregnancy results, in such instance, IVF is similar to coital conception; but IVF is an experimental procedure that requires the fertilisation of more than one ovum, hence resulting in many embryos from which to select. This presents a moral problem for those who believe that human life begins at conception (i.e. fertilisation of the ovum by sperm cells).

The fact that so many embryos are produced deliberately, even with the knowledge that only one or two are required, is another issue for moral deliberation. Some have actually questioned why the outcry against abortion by pro-life groups and relative silence regarding the deliberate destruction of foetuses through IVF. Dena and Davis (2006) put it thus, "If, as prolife activists insist, embryos are morally equivalent to living persons, then why do these activists not oppose in vitro fertilisation (IVF) as aggressively as they oppose abortion?" (p. 275). Driving home the argument, Ord (2008), Citing Tonti-Filippini articulated the argument against destruction of foetuses thus:

The church (Roman Catholic) sees every human life at every stage as equally worthy of protection and the more vulnerable a human being is at a particular stage, the more strenuous should be the community's efforts to protect him or her... Thus from that first moment, that new human being demands the unconditioned respect that is morally due to a human being in his or her bodily and spiritual totality (p. 13).

The alternative to destruction of the foetuses is using them for experimental research or freezing them for future implantation or donation.

The mere idea that human live could be deliberately placed in such a limbo and used in such a manner poses questions of serious moral implication. Since the issue of personhood is very much tied to religious beliefs, it is a serious religious issue to consider in Nigeria. 


\section{CONCLUSION}

Nigeria's values as a nation are constantly being challenged and IVF has the potential of changing human values. The reality of IVF practice in Nigeria has come to stay as is evident from the proliferation of IVF centres in the country. The acceptability which IVF is increasingly receiving makes it imperative that its social-cultural, moral as well as economic implications be carefully considered by Nigeria as a nation. If left on its own i.e. without adequate and proper regulation, IVF can change how Nigerians perceive the person which would rub of on other aspects of interpersonal relationships among citizens.

\section{References}

[1] Ajayi R. A., Osadolor O. J. D., African Journal of Reproductive Health 15(3) (2011) $79-86$.

[2] Carnley P., IVF and Stem cell research. A paper delivered by the Anglican Archbishop of Perth and Primate of Australia at the annual meeting of Bishops, Perth, 18, March 2002.

[3] Dena S. Davis, Houston Journal of Health Law \& Policy 6 (2006) 275-297.

[4] Dominguez-Urban I. (2005). In Vitro fertilisation. In Ethics Vol. 2. California, CA: Salem Press.

[5] Elder K., Dale B. (2000). In vitro fertilisation. Cambridge: Cambridge University Press.

[6] Fisk M. E. C. (2004). A look at the growing and morally complicated world of in-vitro fertilisation. In The Covenant. Pp. 10-12.

[7] Greer G. (1999). The whole woman. Sydney: Transworld.

[8] Inhorn M. C., Anthropology of the Middle-East 1(1) (2006) 42-50.

[9] Liao S.M. (2004). The ethics of using genetic engineering for sex selection. Princeton, NJ: Princeton Universtiy.

[10] NICE. (2004). Assessment and treatment for people with fertility problems. London: National Institute for Clinical Excellence (NICE).

[11] O1 T. M., International Journal of Social Sciences and Humanities 2(4) (2012) 331-334.

[12] Ord T., The American Journal of Bioethics 8(7) (2008) 12-19.

[13] Osazuwa H. (2013). Controversies in In-Vitro Fertilisation. A paper delivered at NISA Premier Hospital, Jabi, Abuja.

[14] Sanusi L. S. (2013). Tertiary institutions, research and innovation and national development: The changing dynamics for sub-Saharan Africa. A paper delivered at the $42^{\text {nd }}$ annual graduation of the Air Force Institute of Technology, Kaduna.

[15] Shahin A., Reproductive Biomedicine Online 15(1) (2007) 51-56.

[16] Upkong D., Orji E., Türk Psikiyatri Dergisi 17 (2006) 259-265. 